\title{
Glucose and Carbachol Generate 1,2-Diacylglycerols by Different Mechanisms in Pancreatic Islets
}

\author{
Bettina Peter-Riesch, Marc Fathi, ${ }^{*}$ Werner Schlegel, ${ }^{\ddagger}$ and Claes B. Wollheim \\ Institut de Biochimie Clinique, ${ }^{*}$ Laboratoire Central de Chimie Clinique, Hôpital Cantonal Universitaire, and ${ }^{\ddagger}$ Fondation pour \\ Recherches Médicales, University of Geneva, 1211 Geneva 4, Switzerland
}

\section{Abstract}

Diacylglycerols (DAG) modulate secretory responses by the activation of protein kinase C. Early changes in DAG formation induced by the muscarinic receptor agonist carbachol were compared to those caused by the nutrient secretagogue glucose in pancreatic islets. Turnover rates of DAG were investigated in radiolabeling experiments, whereas changes in total mass and fatty acid composition of DAG were assessed by gas-liquid chromatography. When islet lipids were labeled to steady state in tissue culture with $\left[^{3} \mathrm{H}\right]$ glycerol, carbachol induced a rapid (10 s) and sustained increase of $\left[{ }^{3} \mathrm{H}\right] \mathrm{DAG}$ generation. In contrast, glucose stimulation failed to increase $\left[{ }^{3} \mathrm{H}\right]$ glycerol containing DAG, and this was probably due to the isotopic dilution of the label secondary to enhanced glycolysis. This was substantiated by following the transfer of ${ }^{14} \mathrm{C}$ from glucose into DAG. Within 1 min of acute exposure of islets to D-[U- $\left.{ }^{14} \mathrm{C}\right]-$ glucose at stimulatory concentrations, DAG labeling increased fivefold representing up to $2 \%$ of total glucose usage. Similar stimulation of ${ }^{14} \mathrm{C}$ incorporation into other neutral lipids and inositol phospholipids was observed, suggesting the enhanced de novo synthesis of phosphatidic acid, the common precursor for DAG, and inositol phospholipids from glycolytic intermediates. Transfer of ${ }^{14} \mathrm{C}$ from glucose was not stimulated by agents such as carbachol and exogenous phospholipase $C$ that act primarily on inositol phospholipid breakdown. The total mass of islet DAG was increased by $60 \%$ after both carbachol and glucose stimulation. However, analysis of the fatty acid composition of carbachol-generated DAG revealed at the early time point (10 s) a prevalent stearoyl-arachidonoyl configuration similar to that reported for inositol phospholipids. This pattern shifted to a DAG enriched in palmitic acid at a later time point. Glucose-stimulated islets displayed a predominance of palmitic acid containing DAG, indicating increased de novo synthesis of the putative second messenger rather than its formation by inositol phospholipid hydrolysis. Indeed, steadystate labeling of these phospholipids with $\left[{ }^{3} \mathrm{H}\right]$ inositol confirmed this idea since only carbachol caused detectable inositol phospholipid hydrolysis. Thus, although protein kinase $\mathbf{C}$ may be activated by both carbachol and glucose, the two secretagogues generate diacylglycerols through different mechanisms.

Address correspondence and reprint requests to Dr. Wollheim, Institut de Biochimie Clinique, Centre Médical Universitaire, 1211 Geneva 4, Switzerland.

Received for publication 27 July 1987.

J. Clin. Invest.

(C) The American Society for Clinical Investigation, Inc.

0021-9738/88/04/1154/08 $\$ 2.00$

Volume 81, April 1988, 1154-1161

\section{Introduction}

Diacylglycerol (DAG) ${ }^{1}$ is postulated to play an important role in cellular activation. Thus, DAG is an endogenous activator of protein kinase $\mathrm{C}$, a $\mathrm{Ca}^{2+}$ - and phospholipid-dependent enzyme known to modulate secretory responses $(1,2)$. Its second messenger role is implied from the fact that it is the product of the phosphodiesteratic cleavage of phosphatidylinositol 4,5bisphosphate (PtdIns 4,5 $\mathrm{P}_{2}$ ), an enzymatic reaction stimulated by a wide variety of receptor agonists (3). Alternatively, DAG can be derived from the glycolytic intermediate dihydroxyacetone phosphate and from glycerol 3-phosphate after stepwise acylation to lyso-phosphatidic acid and phosphatidic acid (PA) $(4,5)$.

Insulin secretion from the pancreatic B cell is stimulated by fuels, neurotransmitters, and hormones (6). The question therefore arises as to how metabolic stimulation and surface receptor activation lead to the same final event, namely enhanced exocytosis of secretory granules. It is generally believed that the triggering of the insulin secretory response requires both a rise in cytosolic free $\mathrm{Ca}^{2+}$ and the activation of protein kinase $C(7,8)$. Carbachol acts via muscarinic receptors coupled to phospholipase $\mathrm{C}$ to produce a rapid rise of inositol 1,4,5-trisphosphate (Ins 1,4,5 $\mathrm{P}_{3}$ ), which mobilizes $\mathrm{Ca}^{2+}$ from an intracellular store $(3,9-11)$. In contrast, the fuel secretagogue glucose depolarizes the B cell membrane and elicits electrical activity, which results in an increase of cytosolic free $\mathrm{Ca}^{2+}$ by opening of voltage-dependent $\mathrm{Ca}^{2+}$ channels during the action potentials $(6,7,12)$. Less information is available with regard to the activation of protein kinase $C$ during carbachol- and glucose-stimulated insulin release. In pancreatic islets and insulinoma cells, the synthetic DAG, 1-oleoyl-2-acetylglycerol, and the tumor promoter 12-O-tetradecanoyl phorbol 13-acetate have been shown to activate protein kinase $\mathrm{C}$ and elicit insulin secretion $(13,14)$. Moreover, the involvement of protein kinase $C$ in the stimulation of islet cells by glucose has recently been underscored by the identification of several proteins, the phosphorylation of which is stimulated both by glucose and by $12-O$-tetradecanoylphorbol 13 -acetate (15). Because of this converging evidence we decided to investigate the early changes of the endogenous activator of protein kinase C, i.e., DAG, during stimulation of pancreatic islets with glucose. The effects of the fuel were compared to those of the muscarinic agonist carbachol. Three experimental approaches were chosen. First, islet DAG was isotopically labeled by the means of $\left[{ }^{3} \mathrm{H}\right]$ glycerol. Secondly, DAG was directly measured by gas-liquid chromatography (GLC) yielding information on total mass and fatty acid composition; the latter

1. Abbreviations used in this paper: DAG, 1,2-diacylglycerol(s); Insl,4,5P $\mathrm{P}_{3}$, inositol 1,4,5-trisphosphate; PA, phosphatidic acid; PtdIns, phosphatidylinositol; PtdIns4P, phosphatidylinositol 4-monophosphate; PtdIns4,5 $\mathrm{P}_{2}$, phosphatidylinositol 4,5-bisphosphate. 
may indicate the origin of secretagogue-induced DAG. Thirdly, the incorporation of $\mathrm{D}-\left[\mathrm{U}-{ }^{14} \mathrm{C}\right]$ glucose metabolites into DAG was followed during agonist stimulation. It was found that both secretagogues raise DAG, albeit via different mechanisms. Our results favor the conclusion that carbachol stimulation of DAG results from enhanced inositol phospholipid breakdown, whereas glucose stimulation of DAG levels is primarily the consequence of enhanced de novo lipid synthesis. These results were supported by measurements of inositol phospholipids, which were either labeled by $\left[{ }^{3} \mathrm{H}\right]$ inositol or $\left[{ }^{3} \mathrm{H}\right]$ glycerol and by following the incorporation of $\mathrm{D}-\left[\mathrm{U}-{ }^{14} \mathrm{C}\right]$ glucose.

\section{Methods}

Pancreatic islets were isolated from male Wistar rats after collagenase digestion and enrichment by centrifugation on a Ficoll gradient. After collagenase digestion the tissue was washed twice and resuspended in $10 \mathrm{ml}$ of a Ficoll solution $(1.085 \mathrm{~g} / \mathrm{ml})$, and two layers of a Ficoll solution $(1.075$ and $1.045 \mathrm{~g} / \mathrm{ml}), 8$ and $4 \mathrm{ml}$, respectively, were carefully layered on top. After a 10 -min centrifugation $\left(800 \mathrm{~g}\right.$ at $\left.20^{\circ} \mathrm{C}\right)$ the upper two layers and approximately one-third of the bottom layer were diluted into $50 \mathrm{ml}$ of a modified $\mathrm{KRB}$ containing $5 \mathrm{mM} \mathrm{NaHCO}, 1$ $\mathrm{mM} \mathrm{CaCl}, 10 \mathrm{mM}$ Hepes, $2.8 \mathrm{mM}$ glucose, and $0.5 \%$ BSA and centrifuged $2 \mathrm{~min}$ at $200 \mathrm{~g}$. The supernatant was aspirated except for the bottom $10 \mathrm{ml} .20 \mathrm{ml}$ of Ficoll $(1.16 \mathrm{~g} / \mathrm{ml})$ was added and the tissue was thoroughly mixed. Then in succession $8 \mathrm{ml}$ of Ficoll $(1.085 \mathrm{~g} / \mathrm{ml})$ and 4 $\mathrm{ml}$ of Ficoll $(1.045 \mathrm{~g} / \mathrm{ml})$ were carefully layered on top. After centrifugation $\left(20 \mathrm{~min}\right.$ at $20^{\circ} \mathrm{C}, 455 \mathrm{~g}$ ) the interphase between the Ficoll layer 1.045 and $1.085 \mathrm{~g} / \mathrm{ml}$ contains virtually all the islets essentially free of exocrine cell aggregates. This interphase was removed and diluted with KRB (0.5\% BSA) and islets were collected under a dissection microscope.

Analysis of islet lipid metabolism using radioactive labeling. Neutral lipids and phospholipids were labeled by maintaining batches of $400-500$ islets for $48 \mathrm{~h}$ in $4 \mathrm{ml}$ of medium 199 containing $10 \%$ heatinactivated newborn calf serum, $8.3 \mathrm{mM}$ glucose, $400 \mathrm{IU} / \mathrm{ml}$ sodium penicillin $\mathrm{G}, 200 \mu \mathrm{g} / \mathrm{ml}$ streptomycin sulfate, $50 \mu \mathrm{g} / \mathrm{ml}$ gentamycin, and $5 \mu \mathrm{Ci} / \mathrm{ml}\left[2{ }^{3} \mathrm{H}\right]$ glycerol or $5 \mu \mathrm{Ci} / \mathrm{ml}$ myo $\left[2^{-3} \mathrm{H}\right]$ inositol.

After labeling the islets were washed with the modified KRB containing $0.07 \%$ BSA or $1 \%$ heat-inactivated newborn calf serum $(\mathrm{pH} 7.4$ at $37^{\circ} \mathrm{C}$ ). Batches of $50-100$ islets were preincubated at $37^{\circ} \mathrm{C}$ for 10 min in $250 \mu \mathrm{l}$ of KRB containing $0.07 \%$ BSA and stimulated by the addition of $250 \mu \mathrm{l}$ of doubly concentrated prewarmed agonist solutions to yield appropriate final concentrations.

The incorporation of glucose-derived ${ }^{14} \mathrm{C}$ into DAG was assessed in another group of experiments, in which islets were only prelabeled with $\left[2-{ }^{3} \mathrm{H}\right]$ glycerol. After the $10-\mathrm{min}$ preincubation at $37^{\circ} \mathrm{C}$ in $250 \mu \mathrm{l}$ of isotope-free buffer, containing $1 \%$ heat-inactivated newborn calf serum, the islets were stimulated with $250 \mu \mathrm{l}$ of doubly concentrated agonist solution in the presence of $\mathrm{D}-\left[\mathrm{U}-{ }^{14} \mathrm{C}\right]$ glucose at a final tracer concentration of $\sim 16$ and $2.7 \mathrm{mCi} / \mathrm{mmol}$ corresponding to a final glucose concentration of 2.8 and $16.7 \mathrm{mM}$, respectively.

For the determination of label incorporated into neutral lipids the incubations were terminated by the addition of ice-cold chloroform/ methanol $(1: 2, \mathrm{vol} / \mathrm{vol})$. For extraction, chloroform and distilled water were added with vigorous mixing to obtain a final ratio of chloroform/ methanol/water $(2: 2: 1)(16)$. After $30-60 \mathrm{~min}$ at $4^{\circ} \mathrm{C}$, samples were centrifuged $(2,000 \mathrm{~g}, 5 \mathrm{~min})$ and the aqueous layer was discarded. After two washes with one part of chloroform and one of water, the solvent lipid extract was evaporated to dryness under a gentle stream of nitrogen at room temperature. Samples were reconstituted in $50 \mu \mathrm{l}$ of chloroform/methanol/water (75:25:2) and DAG were separated from other lipids on silica gel $G$ thin-layer plates, developed in benzene/ether/ ethanol/acetic acid $(25: 20: 1: 0.1)(17,18)$. Neutral lipids were identified by comigrating standards and visualized by iodine staining. Monoacylglycerols were identified as comigrating with monooleoylglycerol
$\left(R_{f} 0.145 \pm 0.004\right)$, DAG were identified as comigrating with 1,2-dipalmitoylglycerol $\left(R_{f} 0.535 \pm 0.002\right)$ with 1,2-distearoylglycerol $\left(R_{f}\right.$ $0.546 \pm 0.002), 1,2$-dioleoylglycerol $\left(R_{f} 0.552 \pm 0.002\right)$. Note that $1,3-$ dioleoylglycerol $\left(R_{f} 0.581 \pm 0.003\right)$ separated well from DAG and that free arachidonic acid $\left(R_{f} 0.433 \pm 0.003\right)$ does not contaminate DAG. Triacylglycerols were identified as comigrating with trioleoylglycerol $\left(R_{f} 0.681 \pm 0.002\right)$. Mono-, di-, and tri-acylglycerols were scraped from the plates into scintillation vials and radioactivity was determined by liquid scintillation counting.

For the determination of label incorporated into phospholipids the incubations were stopped with chloroform/methanol/HCl $12 \mathrm{~N}$ (200:100:0.75). The organic phase was then washed three times with chloroform/methanol/HCl $0.6 \mathrm{~N}$ (3:48:47). After evaporation under nitrogen, phospholipids were separated by thin-layer chromatography (TLC) on silica gel G plates pretreated with potassium oxalate and developed in a solvent system containing chloroform/methanol/acetone/water/acetic acid (35:13:15:8:12). Inositol phospholipid standards, including phosphoinositides (PtdIns, PtdIns4P, PtdIns4,5 $\mathbf{P}_{2}$, $\sim 10 \mu \mathrm{g}$ each) were added to each sample and visualized by iodine staining (19). Corresponding areas were scraped off and radioactivity was determined by liquid scintillation counting in the presence of 0.5 $\mathrm{ml}$ of water and $10 \mathrm{ml}$ of hydroluma using an LS 7500 scintillation counter (Beckman Instruments, Inc., Palo Alto, CA).

Analysis of total mass and fatty acid composition of DAG by GLC. Batches of 250 freshly isolated islets were preincubated at $37^{\circ} \mathrm{C}$ in 900 $\mu$ l of KRB $(0,07 \% \mathrm{BSA})$ in the presence of $2.8 \mathrm{mM}$ glucose for $30 \mathrm{~min}$. The stimulation was started by the addition of $100 \mu$ l of the same buffer containing the test substances as described above and terminated exactly as detailed for neutral lipids. For the purification of DAG identical procedures as for labeled neutral lipids were followed. To preserve unsaturated fatty acid species, butylated hydroxyltoluene $0.05 \%$ (wt/ vol) was present in the extracting solvent and in all subsequent solvent systems. Furthermore, all manipulations were carried out at $4^{\circ} \mathrm{C}$ and under nitrogen whenever possible. After the separation of DAG on TLC (see above) the corresponding area was identified by visualization of the DAG standards, run in separate lanes on the same plate, under ultraviolet light after spraying the plates with an ethanol solution of rhodamine $6 \mathrm{G}$. Rhodamine $6 \mathrm{G}$ was preferred to iodine to preserve the integrity of the lipid molecules (20). The spots containing DAG were scraped and transferred into teflon-capped pyrex glass tubes. After addition of $5 \mathrm{ml}$ of methanol containing $1 \%$ concentrated $\mathrm{H}_{2} \mathrm{SO}_{4}$ ( $\mathrm{vol}$ / vol) tubes were flushed with nitrogen, and then transmethylation was performed at $70^{\circ} \mathrm{C}$ for $3 \mathrm{~h}$. Before and after transmethylation tubes were weighed to detect possible evaporation. Fatty acid methylesters were extracted twice with $3 \mathrm{ml}$ of petroleum ether (b.p. $40-60^{\circ} \mathrm{C}$ ). Then an aliquot of the fatty acid methylesters was chromatographed on a $200-\mathrm{cm}$ glass column with an internal diameter of $3 \mathrm{~mm}$. The column was packed with $10 \%$ SP-2330 on $100 / 120$ Chromosorb (W AW). Analysis was performed on a Carlo Erba gas chromatograph equipped with a flame ionization detector. Nitrogen was used as the carrier gas at a flow rate of $24 \mathrm{ml} / \mathrm{min}$. The column temperature was set at $180^{\circ} \mathrm{C}$ isotherm for $9 \mathrm{~min}$ and raised to $200^{\circ} \mathrm{C}$ by $3^{\circ} \mathrm{C} / \mathrm{min}$. The gas chromatograph was calibrated using a standard mixture of methylated fatty acids. Yields of reactions were determined by adding known amounts of heneicosanoic methyl ester to the petroleum ether extraction just before GLC. Recovery of DAG, determined by processing known amounts of standard DAG in parallel was found to be $82 \pm 3 \%$. Integration of GLC peaks was performed using an integrator (model 3390, Hewlett-Packard Co., Palo Alto, CA).

This method is a modification of earlier described procedures (18, 21). To evaluate our methodology we also measured DAG in human neutrophils and rat hepatocytes. In pancreatic islets we obtained a total DAG content of $0.27 \pm 0.01 \mathrm{nmol}$ per 100 islets $(n=10)$ corresponding to $6 \mathrm{pmol} / \mu \mathrm{g}$ protein (assuming an average molecular weight of 625 for DAG and $0.4 \mu \mathrm{g}$ of protein per islet). In hepatocytes we found a total DAG content of $0.19 \pm 0.01 \mathrm{nmol} / \mathrm{mg}$ wet weight $(n=11)$ corresponding to $0.95 \mathrm{pmol} / \mu \mathrm{g}$ protein. This can be compared to results published for hepatocytes; one group reported $1.48 \mathrm{nmol} / \mathrm{mg}$, wet weight of cells 
or $7.4 \mathrm{pmol} / \mu \mathrm{g}$ protein $(21)$ while another reported $0.21 \mathrm{nmol} / \mathrm{mg}$ wet weight or $1 \mathrm{pmol} / \mu \mathrm{g}$ protein (22). Finally, we measured a value of $2.8 \pm 0.05 \mathrm{nmol} / 10^{8}$ cells of total DAG in human neutrophils $(n=3)$, close to the reported value for this cell type of $2 \mathrm{nmol} D A G / 10^{8}$ cells (23).

Results are shown as mean \pm standard error for the number of observations indicated. Statistical analysis was made by Student's $t$ test for unpaired data.

The sources of all materials were as previously described (24), except for neutral lipid and phospholipid standards, carbachol, and phospholipase C (Clostridium perfringens), which were purchased from Sigma Chemie, Munich, Federal Republic of Germany (FRG). All solvents of the best analytical grade commercially available, were from Merck Darmstadt, FRG, as were the silica gel $G$ plates. Fatty acid methylester standards and rhodamine 6G were from Supelco, Houston, TX. Isotopes were from Amersham International Plc, Bucks., United Kingdom.

\section{Results}

Glycerol labeling of $D A G$. DAG labeling with $\left[{ }^{3} \mathrm{H}\right]$ glycerol reaches a steady state after $48 \mathrm{~h}(160 \pm 24,245 \pm 16,221 \pm 24$ cpm per 100 islets at 24,48 , and $72 \mathrm{~h}$, respectively). Prolonged labeling results in a condition close to isotopic equilibrium in which alterations in radioactivity most likely reflect quantitative changes, unless the isotopic conditions are perturbed upon stimulation. Indeed, carbachol, which acts primarily to activate phospholipase $C$ causes a rapid and sustained increase in DAG. In contrast, glucose does not change ${ }^{3} \mathrm{H}$ labeled DAG (Fig. 1). This could be due to the perturbation of the isotopic steady state by the increase in extracellular glucose. The increase in extracellular glucose from 2.8 to $16.7 \mathrm{mM}$ is known to lead to massive acceleration of glucose metabolism (24): unlabeled trioses from glycolysis could cause a chase of $\left[{ }^{3} \mathrm{H}\right]-$ glycerol label from neutral lipids masking the overall increase in DAG.

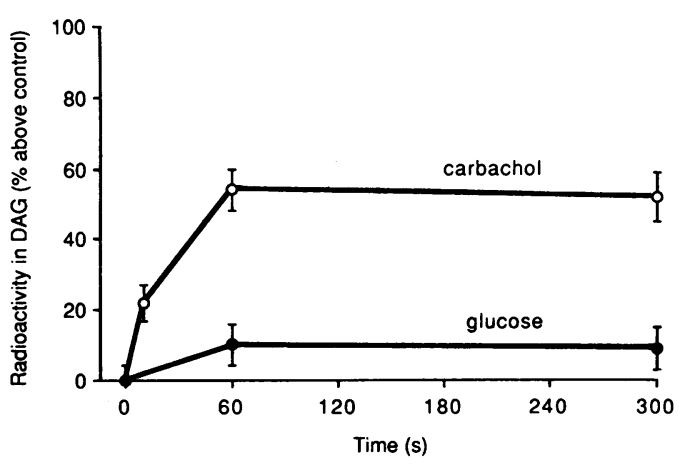

Figure 1. Time-dependent changes of DAG in islets labeled to steady state with $\left[{ }^{3} \mathrm{H}\right] \mathrm{glycerol}$ after stimulation with carbachol $(0.5 \mathrm{mM})$ and glucose (16.7 mM). Islets were labeled in medium 199 containing $10 \%$ newborn calf serum, $8.3 \mathrm{mM}$ glucose, and $5 \mu \mathrm{Ci} / \mathrm{ml}\left[2-{ }^{3} \mathrm{H}\right]-$ glycerol during $48 \mathrm{~h}$. Groups of 50 islets were then preincubated at $37^{\circ} \mathrm{C}$ for $10 \mathrm{~min}$ in $250 \mu \mathrm{l}$ of KRB containing $0.07 \%$ BSA and then stimulated with $250 \mu \mathrm{l}$ of the same buffer containing agonists to yield appropriate final concentrations. Reactions were stopped by the addition of chloroform/methanol and radioactivity in DAG was determined after extraction and TLC as described in Methods. Control islets incubated under identical conditions in the absence of stimulators maintained stable levels of ${ }^{3} \mathrm{H}$-labeled DAG which averaged $119 \pm 6 \mathrm{cpm}(n=53)$. Shown are the mean \pm SE of $20-30$ determinations.
Rapid incorporation of glucose metabolites into neutral and phospholipids. The effects of glucose on the turnover of DAG can be tested measuring acute DAG labeling from $\mathrm{D}-\left[\mathrm{U}-{ }^{14} \mathrm{C}\right]-$ glucose. To this end, islets labeled to steady state with $\left[{ }^{3} \mathrm{H}\right]-$ glycerol are exposed to $\mathrm{D}-\left[\mathrm{U}-{ }^{14} \mathrm{C}\right]$ glucose simultaneously with stimulation. As is shown in Fig. 2, the transfer of ${ }^{14} \mathrm{C}$ from D-glucose to DAG is markedly enhanced at elevated glucose levels, being stimulated five- and eight-fold at 1 and $30 \mathrm{~min}$, respectively. Stimulation by high glucose of ${ }^{14} \mathrm{C}$ transfer from glucose to DAG is unaffected by lowering of extracellular $\mathrm{Ca}^{2+}$ by addition of EGTA. However, it is inhibited by the addition of mannoheptulose, an inhibitor of glucose metabolism that blocks its phosphorylation in islets (25). The appearance of glucose metabolites in neutral lipids is unaffected by stimuli that enhance DAG levels selectively. Neither carbachol (Fig. 1) nor phospholipase $\mathrm{C}$, the latter raising $\left[{ }^{3} \mathrm{H}\right]$ glycerol-labeled DAG from $197 \pm 19$ to $1088 \pm 123$ (cpm/100 islets) in $1 \mathrm{~min}$, alter the transfer of label from glucose to neutral lipids (Fig. 2).

These experiments on ${ }^{14} \mathrm{C}$ transfer were carried out in medium containing $1 \%$ heat-inactivated newborn calf serum based on an earlier report in which the incorporation was claimed to depend on the fatty acid availability (5). This dependency was investigated in two experiments in which the serum had been replaced by $0.07 \%$ BSA. Again, glucose stimulation for $1 \mathrm{~min}$ resulted in a sixfold increase of ${ }^{14} \mathrm{C}$ incorporation into DAG (data not shown). The effect of glucose is therefore not dependent on the presence of serum. The experiments on ${ }^{14} \mathrm{C}$ transfer thus confirm that glycolytic metabolites appear very rapidly in neutral lipids. More importantly, they suggest that at high glucose levels the de novo synthesis of lipids is accelerated.

This is further substantiated by measurements of other neutral lipids (Table I) and the most rapidly turning over phospholipids, the inositol phospholipids (Fig. 3). Elevated glucose

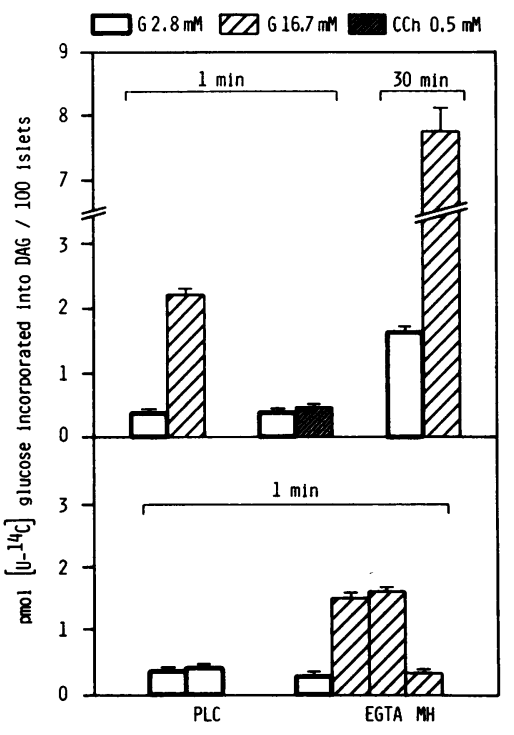

Figure 2. Acute transfer of ${ }^{14} \mathrm{C}$ from D-[U- $\left.{ }^{14} \mathrm{C}\right]$ glucose to DAG of rat pancreatic islets. Islets were cultured as described in the legend to Fig. 1. Batches of 100 islets were preincubated for $10 \mathrm{~min}$ at $37^{\circ} \mathrm{C}$ in $250 \mu$ l of KRB containing $1 \%$ heat-inactivated newborn calf serum and then acutely exposed to D- $\left[\mathrm{U}-{ }^{14} \mathrm{C}\right] \mathrm{glucose}$ by adding $250 \mu \mathrm{l}$ of the same buffer containing doubly concentrated agonist concentrations. D$\left[\mathrm{U}-{ }^{14} \mathrm{C}\right] \mathrm{glucose}$ was present at a final tracer concentration of $\sim 16$ and $2.7 \mathrm{mCi} / \mathrm{mmol}$ at a

glucose concentration of 2.8 and $16.7 \mathrm{mM}$, respectively. The final concentration of phospholipase $\mathrm{C}(P L C)$ was $2 \mathrm{U} / \mathrm{ml}$ and that of mannoheptulose $(M H) 20 \mathrm{mM}$. The results for $\left[{ }^{3} \mathrm{H}\right] \mathrm{glycerol}-$ labeled DAG are given in Table I. Shown are the mean \pm SE $(n=6-9$, upper panel; $n=3$, lower panel). The data were calculated based on the specific radioactivity of glucose in the medium. $G$, glucose; $C C h$, carbachol. 
Table I. Effect of Glucose on Islet Neutral Lipids

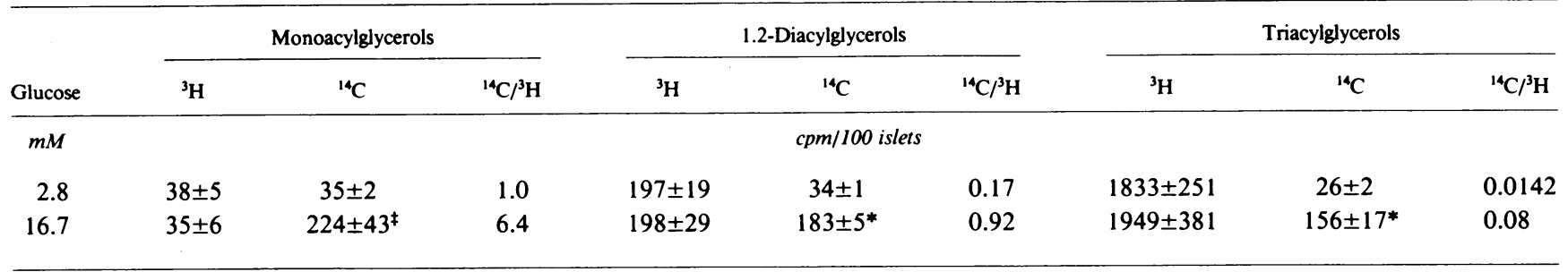

Islets were steady-state labeled during culture with $\left[{ }^{3} \mathrm{H}\right]$ glycerol and acutely exposed to $\mathrm{D}-\left[\mathrm{U}-{ }^{14} \mathrm{C}\right]$ glucose as described in the legend to Fig. $2 .{ }^{14} \mathrm{C}$ and ${ }^{3} \mathrm{H}$ content of neutral lipids was determined from chloroform/methanol-extracted samples after further TLC separation. Incubations were for $1 \mathrm{~min}$. The results are shown as the mean $\pm \mathrm{SE}(n=6-8)$. Statistically significant differences between glucose 2.8 and $16.7 \mathrm{mM}$ are indicated: ${ }^{*} P<0.001 ;{ }^{\ddagger} P<0.01$.

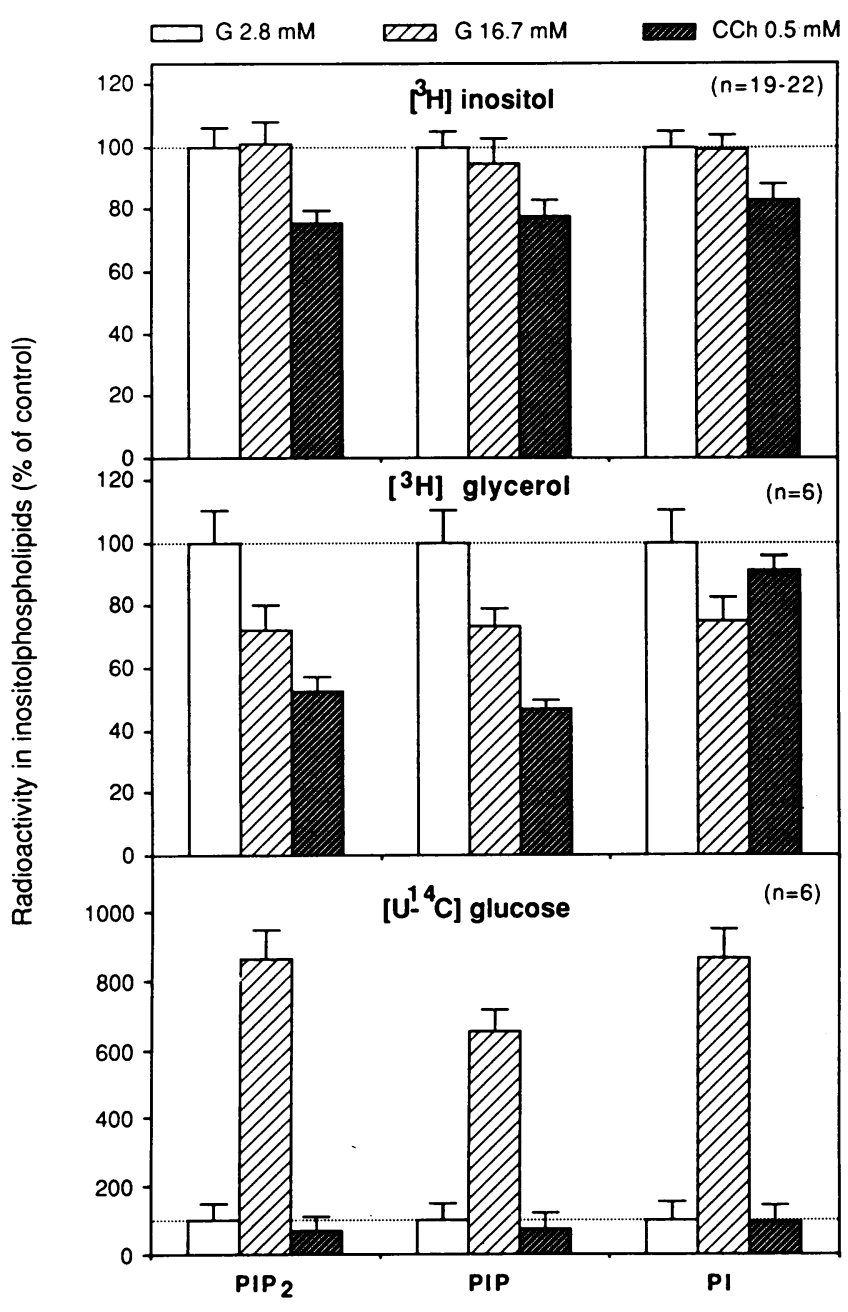

Figure 3. Effects of glucose and carbachol on islet inositol phospholipids measured as changes in $\left[{ }^{3} \mathrm{H}\right]$ inositol or $\left[{ }^{3} \mathrm{H}\right]$ glycerol labeling and as $\left[{ }^{14} \mathrm{C}\right]$ transfer from $\mathrm{D}-\left[\mathrm{U}-{ }^{14} \mathrm{C}\right]$ glucose. Islet culture and incubation were as described in the legend to Fig. $2 ; 5 \mu \mathrm{Ci} / \mathrm{ml}$ of either [2$\left.{ }^{3} \mathrm{H}\right]$ glycerol or myo $\left[2-{ }^{3} \mathrm{H}\right]$ inositol was present. Islets were exposed to agonists and $\mathrm{D}-\left[\mathrm{U}-{ }^{14} \mathrm{C}\right] \mathrm{glucose}$ for $1 \mathrm{~min}$. Inositol phospholipids were extracted with acidic chloroform/methanol and separated by TLC as described in Methods. Shown are the means $\pm \operatorname{SE}(n=6)$. The effect of agonists on $\left[{ }^{3} \mathrm{H}\right]$ glycerol-labeled PtdIns $4,5 \mathrm{P}_{2}$ and PtdIns $4 \mathrm{P}$ was significant; $P<0.05$ and $<0.005$ for glucose and carbachol, respectively. Carbachol significantly decreased $\left[{ }^{3} \mathrm{H}\right]$ inositol-labeled PtdIns4,5P ${ }_{2}$, PtdIns4P, and PtdIns $(P<0.001,<0.005,<0.05$, respectively). $P I P_{2}$, PtdIns4,5P ${ }_{2} ; P I P$, PtdIns4P; $P I$, PtdIns. levels lead to a significantly enhanced incorporation of glucose metabolites into monoacyl-, 1,2-diacyl-, and triacylglycerols within the first minute of stimulation. Glucose stimulation appears to enhance predominantly the incorporation of ${ }^{14} \mathrm{C}$ from glucose into the glycerol backbone of neutral lipids. This is apparent from the fact that the ${ }^{14} \mathrm{C} /{ }^{3} \mathrm{H}$ ratio increases to a similar extent five- to six-fold in mono-, di-, and triacylglycerols reflecting the same enhancement of glucose metabolite incorporation irrespective of the number of fatty acid side chains (Table I).

The changes in neutral lipids occurring upon glucose stimulation of cultured islets described above are paralleled by changes in inositol phospholipids. Due probably to the rapid turnover of these phospholipids, it is possible to monitor the acute appearance of $\left[{ }^{14} \mathrm{C}\right]$ glucose metabolites. Glucose stimulation leads within the first minute to a six- to eight-fold increase in inositol phospholipid labeling from glucose. All three inositol phospholipids are labeled to the same extent suggesting that the label appearing in PtdIns is extremely rapidly reequilibrated into PtdIns4 4 and PtdIns4,5 $\mathrm{P}_{2}$. Interestingly, the stimulation of glucose carbon transfer into inositol phospholipids is stimulated to the same degree by glucose as the transfer into neutral lipids, suggesting a common underlying pathway such as the de novo synthesis of PA, a precursor for both PtdIns and DAG (Table I, Fig. 3) $(5,26)$.

The acceleration of glucose metabolism by elevated glucose levels also perturbs the isotopic steady state in islet inositol phospholipids reached after prolonged exposure to $\left[{ }^{3} \mathrm{H}\right]-$ glycerol. This is apparent from a reduction of ${ }^{3} \mathrm{H}$ label in all the inositol phospholipids (Fig. 3, middle panel). The failure to observe enhanced $\left[{ }^{3} \mathrm{H}\right]$ glycerol-labeled DAG levels after glucose stimulation (Fig. 1) can also be explained by a chase of the $\left[{ }^{3} \mathrm{H}\right]$ glycerol label from neutral as from phospholipids.

In contrast to glucose stimulation which leads to reduced $\left[{ }^{3} \mathrm{H}\right]$ glycerol label in all three inositol phospholipids, carbachol causes a selective loss of $\left[{ }^{3} \mathrm{H}\right] \mathrm{PtdIns} 4,5 \mathrm{P}_{2}$ and PtdIns4P. This is not associated with increased incorporation of glucose-derived ${ }^{14} \mathrm{C}$ atoms and therefore represents a net breakdown of PtdIns4,5 $\mathrm{P}_{2}$ (Fig. 3). Moreover, this decrease is greater than that seen with glucose even when the isotopic dilution effect is ignored, indicating that carbachol must induce a much greater hydrolysis of PtdIns4,5 $\mathrm{P}_{2}$ than glucose. It appears that elevated glucose levels and enhanced glucose metabolism accelerate the incorporation of glucose metabolites into neutral and phospholipids; however, it remains unclear whether de novo synthesis rates of lipids are truly enhanced. The quantitative increase in DAG levels after glucose stimulation, described 
Table II. Changes in Total Mass and Fatty Acid Composition of Islet DAG during Carbachol or Glucose Stimulation

\begin{tabular}{|c|c|c|c|c|c|c|c|}
\hline Additions & $\begin{array}{l}\text { Incubation } \\
\text { time }\end{array}$ & $n$ & Total DAG & Palmitic acid & Stearic acid & Oleic acid & $\begin{array}{l}\text { Arachidonic } \\
\text { acid }\end{array}$ \\
\hline & $s$ & & & & ng/100 islets & & \\
\hline \multirow[t]{3}{*}{ Carbachol $0.5 \mathrm{mM}$} & 10 & 7 & $126 \pm 15^{*}$ & $29 \pm 12$ & $54 \pm 13^{\ddagger}$ & $5 \pm 2$ & $40 \pm 6^{\ddagger}$ \\
\hline & 60 & 2 & 119 & 54 & 16 & 14 & 24 \\
\hline & 300 & 6 & $100 \pm 20^{*}$ & $72 \pm 11^{*}$ & $16 \pm 5$ & $0 \pm 2$ & $24 \pm 4$ \\
\hline Glucose $16.7 \mathrm{mM}$ & 300 & 10 & $87 \pm 17^{*}$ & $74 \pm 13^{*}$ & $15 \pm 11$ & $1 \pm 2$ & $7 \pm 2.8$ \\
\hline
\end{tabular}

Islets were incubated in $\mathrm{KRB}(0.07 \% \mathrm{BSA})$ containing glucose 2.8 or $16.7 \mathrm{mM}$, or carbachol $0.5 \mathrm{mM}$ in the presence of $2.8 \mathrm{mM}$ glucose for the time indicated. After chloroform/methanol extraction, islet DAG were analyzed by TLC, transmethylation, and GLC as described under Methods. Results are shown as incremental changes of total mass and the fatty acids, respectively (expressed as the delta fatty acid mass derived from DAG per 100 islets) and are the means \pm SE. Total DAG-derived fatty acid mass of unstimulated samples averaged $202 \pm 7,187 \pm 9$, $200 \pm 22$, and $166 \pm 7 \mathrm{ng}$ per 100 islets at $10,60,300$, and $300 \mathrm{~s}$ respectively. Islets incubated for $5 \mathrm{~min}$ in the presence of $2.8 \mathrm{mM}$ glucose contained $49 \pm 7,39 \pm 3,40 \pm 4$, and $37 \pm 5 \mathrm{ng}$ for palmitic, stearic, oleic, and arachidonic acid, respectively. Values significantly different from control are indicated: ${ }^{*} P<0.001 ;{ }^{\ddagger} P<0.05$.

below, strongly supports the idea of an acceleration of de novo synthesis of lipids possibly triggered by the increase in glucose metabolites.

This contention is further substantiated from the results of $\left[{ }^{3} \mathrm{H}\right]$ inositol labeling of islet phospholipids shown in Fig. 3 (upper panel). Under these conditions only carbachol causes decreases in all three inositol-phospholipids. In contrast, glucose stimulation does not result in any change in the steadystate labeled $\left[{ }^{3} \mathrm{H}\right]$ inositol phospholipids. This does not mean that glucose is unable to cause hydrolysis of PtdIns4,5 $\mathrm{P}_{2}$, since under the same labeling conditions small increases of Ins $1,4,5 \mathrm{P}_{3}$ have been demonstrated which are smaller than those induced by carbachol (27). These apparently discrepant results, i.e., Ins $1,4,5 \mathrm{P}_{3}$ production without changes in PtdIns4,5 $\mathrm{P}_{2}$ levels can be explained by the availability of $\left[{ }^{3} \mathrm{H}\right]-$ inositol for the resynthesis of the inositol phospholipids. It should be pointed out that we did not alter the steady-state labeling conditions adding nonradioactive inositol. In view of these difficulties it is commendable to measure islet-lipid mass by techniques not involving isotopic labeling. Such an approach was recently reported for the major phospholipid classes investigated after $30 \mathrm{~min}$ of glucose stimulation (28). As there was no change in PtdIns, we have focused our study on the changes in DAG and its fatty acid composition, in an attempt to substantiate further the difference in glucose and carbachol-induced generation of DAG. The changes in this lipid were assessed in a limited number of experiments.

Biphasic alteration in islet DAG after muscarinic receptor activation. The determination of fatty acids in DAG by GLC allows the assessment of quantitative changes in DAG levels, as well as alterations in the overall distribution of different fatty acid species in DAG.

Four major species of fatty acids were identified, i.e., palmitic acid (C16:0), stearic acid (C18:0), oleic acid (C18:1), and arachidonic acid (C20:4), which are present in approximately equal amounts in islets maintained for $5 \mathrm{~min}$ in $\mathrm{KRB}$ with low glucose $(2.8 \mathrm{mM})$ (Table II).

Stimulation of islets with carbachol leads without an apparent lag to an elevation of total DAG mass by $\sim 60 \%$ and significantly enhanced DAG levels are maintained for at least $5 \mathrm{~min}$. Carbachol is known to accelerate phosphodiesteratic cleavage of $\mathrm{PtdInsP}_{2}(7,11,27,29,30)$. This cleavage should yield DAG containing preferentially stearate and arachidonate, since the inositol phospholipids exhibit this fatty acid composition (31). In Table II it is shown that this is indeed the case for early times after carbachol addition: $10 \mathrm{~s}$ after stimulation, both arachidonate and stearate levels in DAG are signifcantly $(P<0.05)$ enhanced. However, the rise in these DAG species is transient, since the levels are reduced at 1 and $5 \mathrm{~min}$ relative to the peak value and remain only slightly higher than control. The persistent elevation of total DAG levels is due to palmitic acid containing DAG the level of which rises continuously during the first $5 \mathrm{~min}$ of carbachol stimulation.

The response of DAG to carbachol stimulation is thus biphasic, a feature only appreciable from the detailed analysis of fatty acid content. The first transient phase of the response is consistent with the activation of $\mathrm{PtdIns}_{2}$ phosphodiesterase yielding the corresponding DAG species presumably in the plasma membrane. The second phase is a maintained elevation of palmitic acid containing DAG.

Glucose stimulation enhances DAG mass. The time course of alterations in DAG mass during stimulation with $16.7 \mathrm{mM}$ glucose was assessed in one experiment performed in duplicate. ${ }^{2}$ As is shown in Fig. 4, glucose stimulation of rat pancreatic islets results in an increase in the total mass of DAG. This increase occurs after a lag of $30 \mathrm{~s}$ such that at $1 \mathrm{~min}$ DAG levels are raised by $>50 \%$, and elevated DAG levels are maintained for at least $10 \mathrm{~min}$.

Glucose stimulation causes a significant alteration of the fatty acid composition of DAG. The fatty acid composition of islet DAG was analyzed after $5 \mathrm{~min}$ of glucose stimulation (Table II). Glucose enhances DAG containing palmitic acid and a slight but not significant rise in stearic acid containing DAG, whereas the oleic acid and arachidonic acid content of DAG is unaltered by sustained glucose stimulation. Consequently, the overall fatty acid composition of DAG is markedly changed resulting in a predominantly (43\%) palmitic acid containing species. As anticipated from the data in Fig. 4, the increase in palmitic and stearic acid containing DAG add up to an overall enhancement of DAG levels by $54 \%$ (Table II).

2. Glucose stimulation is defined as an increase in the glucose concentration of the medium from a basal value $(2.8 \mathrm{mM})$ to a level which maximally stimulates insulin secretion $(16.7 \mathrm{mM})$. 


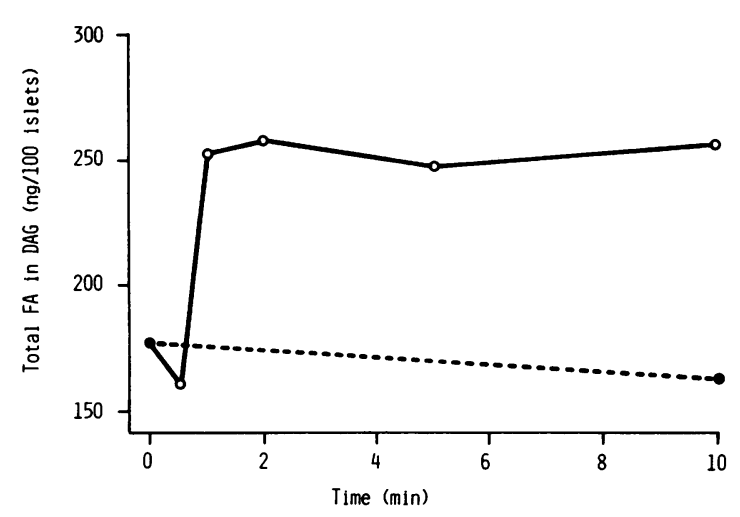

Figure 4. Time course of changes in DAG mass after glucose stimulation of pancreatic islets. Batches of 250 isolated islets were preincubated at $37^{\circ} \mathrm{C}$ in $\mathrm{KRB}$ containing $0.07 \%$ BSA in the presence of 2.8 $\mathrm{mM}$ glucose for $30 \mathrm{~min}$. Islets were stimulated at time zero by the addition of the same buffer containing glucose to yield a final concentration of $16.7 \mathrm{mM}$. Total mass of generated DAG was measured by GLC of fatty acid methylesters derived from chloroform/methanol-extracted and TLC-purified DAG.

In summary, DAG levels in pancreatic islets appear to be enhanced during stimulation by at least two mechanisms, the first being the phosphodiesteratic cleavage of $\mathrm{PtdInsP}_{2}$, the second most probably related to enhanced de novo synthesis of phospholipids and neutral lipids. Receptor mediated activation of B cells can trigger both mechanisms whereas metabolic stimulation of DAG levels reflects predominantly enhanced de novo synthesis.

\section{Discussion}

Increased turnover of inositol phospholipids is known to give rise to the two second messengers DAG and Ins1,4,5P $\mathrm{P}_{3}(3)$. While many studies have addressed the latter compound, information on DAG formation is restricted to the two reports in intact pancreatic endocrine cells (32) and islet cell membranes (33), in which the compound has been measured by prelabeling neonatal islets with $\left[{ }^{14} \mathrm{C}\right]$ arachidonic acid. The present study demonstrates for the first time that DAG mass and DAG fatty acid composition are differentially affected by glucose and carbachol.

At first sight, the additional observation that glucose fails to increase $\left[{ }^{3} \mathrm{H}\right]$ glycerol containing DAG seems surprising, but is probably explained by the high glycolytic rate in islets and the formation of unlabeled triose-phosphates which would dilute the $\left[{ }^{3} \mathrm{H}\right]$ glycerol pool during glucose exposure. This idea was reinforced by the demonstration that radioactive glucose carbon can be detected in DAG as early as 1 min after stimulation. Furthermore, mannoheptulose, a potent inhibitor of glucose phosphorylation (25) completely blocks the incorporation of glucose carbon, thereby attesting to the specificity of this effect. It is also of interest that the incorporation is not affected by the omission of extracellular $\mathrm{Ca}^{2+}$, a maneuver which does not inhibit glucose metabolism by the islets (24). Stimulation of phospholipid breakdown leading to an increase in DAG formation does not favor glucose carbon incorporation. Thus the addition of exogenous phospholipase $C$ which raises DAG levels fivefold and has been shown to stimulate insulin release $(34,35)$ does not increase glucose-derived ${ }^{14} \mathrm{C}$ labeling of
DAG. Similarly, activation of endogenous phospholipase C, best achieved in insulin secreting cells by carbachol $(11,27$, 29), does not enhance transfer of ${ }^{14} \mathrm{C}$ from glucose to DAG at an early time point $(1 \mathrm{~min})$. Indeed, muscarinic receptor agonists have been suggested to increase glycolytic flux in islets only at later time points (36). In three studies with islets attempts have been made to analyze PA, which is both a precursor and a metabolite of DAG. In one of these reports, phospholipids were prelabeled to apparent steady state with ${ }^{32} \mathrm{P}$. Glucose elicited an early and sustained increase in PA, reflecting de novo synthesis of the DAG precursor (26). Another study where both glucose and carbachol increased ${ }^{32} \mathrm{P}$ labeling of islet PA is difficult to interpret because of the non-steady-state labeling conditions (37). The results may either reflect increased turnover through the phosphatidylinositol cycle or de novo synthesis. The same criticism pertains to another report where carbachol and glucose increased $\left[{ }^{3} \mathrm{H}\right]$ glycerol labeling of PA during a 90-min incubation (38).

It should be noted that a sizeable amount, $\sim 0.6 \%$ and $1.7 \%$ of total glucose utilization at 2.8 and $16.7 \mathrm{mM}$ glucose, respectively, is recovered in DAG at $1 \mathrm{~min}$. This calculation is based on the data of Janjic and Wollheim (24). A similar rate of incorporation into triacylglycerols has been reported for glucose-stimulated ob/ob mouse islets (4). However, in neonatal islets a much larger fraction of glucose carbon was recovered in DAG (5), more than can be accounted for by the higher rate of glucose metabolism in such islets (39). Our data (Table I) suggest that a large proportion of the acutely incorporated glucose carbon is associated with the glycerol backbone and not with the acyl chains of DAG. In addition, in glucose-stimulated ob/ob mouse islets $<4 \%$ of the radioactivity incorporated from $\left[{ }^{14} \mathrm{C}\right]$ glucose into neutral lipids was recovered in the fatty acid moieties even after $3 \mathrm{~h}$ of incubation (4). Moreover, the findings that phosphatidate phosphohydrolase activity, catalyzing the dephosphorylation of PA to DAG is stimulated in islets preexposed to glucose, lends further support to the idea that this pathway is operative in stimulated islets (40).

Radioactive labeling techniques can yield some information about the turnover of DAG. However, to obtain quantitative data on DAG mass and fatty acid composition a timeconsuming multistep analysis involving DAG isolation, trans- • methylation, and GLC was necessary. The complexity of this analysis limits the number of data points. Glucose elicits maximal increases in islet DAG at $1 \mathrm{~min}$ and this level remained elevated for $10 \mathrm{~min}$. Interestingly, there is no increase after $30 \mathrm{~s}$ of exposure to glucose. Indeed, glucose metabolism in isolated islets is stimulated around this time point, but insulin release lags behind $(6,41)$. However, in studies on the perfused pancreas, it was not possible to dissociate the accumulation of intermediates such as dihydroxyacetonephosphate from the secretory response already observed at $24 \mathrm{~s}$ (42). In islets stimulated for $5 \mathrm{~min}$ with $16.7 \mathrm{mM}$ glucose, analysis of the fatty acid composition of DAG was performed and showed a predominance of palmitic acid. This is consistent with an increased palmitic acid incorporation into islet neutral and phospholipids after long-term glucose stimulation (43).

Carbachol also increases total islet DAG to a similar extent as glucose, but in this case the increase is already observed at $10 \mathrm{~s}$. The fatty acid composition of DAG varies as a function of time of exposure to carbachol. The inositol phospholipids of many tissues are characterised by a preferential 1-stearoyl 2arachidonoyl fatty acid composition at the $s n$-glycerol back- 
bone (31). This pattern was found in DAG at the early (10 s) time point, whereas at 5 min palmitic acid-enriched DAG predominated. The early change is therefore compatible with the well-documented rapid breakdown of inositol phospholipids in response to carbachol $(11,27,29,30)$. The predominance of palmitic acid containing DAG after prolonged incubation with carbachol may reflect increased glycolysis which has been reported to occur after continuous exposure to muscarinic agonists (36). Moreover, a source other than inositol phospholipids has been implemented in the sustained increase of DAG seen in other tissues in response to receptor agonists (44-46).

Only limited information is available on receptor-agonist induced changes in fatty acid composition of DAG in other tissues. In vasopressin stimulated hepatocytes one laboratory reported enrichement in both stearic and arachidonic acid after $1 \mathrm{~min}$ of exposure to the agonist (21), while another found increases in stearic and less changes in arachidonic acid content (22). However the smaller increase of arachidonic acid could have been due to oxidation of this labile fatty acid during the HPLC purification. On the other hand, DAG in human neutrophils after activation with the chemotactic peptide formylmethionyl-leucyl-phenylalanine did not display the fatty acid pattern expected from inositol phospholipid breakdown at early time points, suggesting a distinct precursor for DAG (23).

Glucose and carbachol appear to trigger distinct mechanisms leading to enhanced DAG levels. Although glucose generates some Ins $\mathrm{P}_{3}$ by PtdIns4,5 $\mathrm{P}_{2}$ hydrolysis the effect is less marked than that of carbachol $(27,29,47)$. Glucose stimulation of PtdIns4,5 $\mathrm{P}_{2}$ hydrolysis appears to depend on the presence of extracellular $\mathrm{Ca}^{2+}(7,27,48,49)$. This $\mathrm{Ca}^{2+}$ dependency is consistent with a $\mathrm{Ca}^{2+}$-mediated activation of phospholipase $C(27,50)$. Our data on the enhanced generation of DAG by glucose are not contradictory to the above observations but indicate that only a minor portion is derived from inositol phospholipid hydrolysis. This conclusion, is supported by our measurements of inositol phospholipids where carbachol caused a larger drop in glycerol-labeled polyphosphoinositides than glucose. Taking into account the demonstrated isotope dilution after glucose stimulation the real decrease must be even smaller (Fig. 3, upper panel). In fact, after labeling with $\left[{ }^{3} \mathrm{H}\right]$ inositol, glucose-induced $\mathrm{PtdIns} \mathrm{P}_{2}$ hydrolysis is not detectable as a lowering of $\left[{ }^{3} \mathrm{H}\right] \mathrm{PtdIns} \mathrm{P}_{2}$ levels.

In conclusion, the present study provides clear evidence that both the nutrient secretagogue glucose and the receptor agonist carbachol increase DAG in pancreatic islets, assessed directly as changes in mass and consistent with the observed alterations in turnover rates. In the case of carbachol, the generation of DAG early after stimulation arises from enhanced hydrolysis of inositol phospholipids with a concomitant rise in Ins 1,4,5 $\mathrm{P}_{3}(27,29,47)$. Glucose generates DAG mainly by stimulating its de novo synthesis. Based on the fatty acid composition of glucose-generated DAG, PtdIns $4,5 \mathrm{P}_{2}$ hydrolysis does not seem to contribute to a significant extent to the increase in DAG mass. Because of the different pathways of DAG generation the question arises whether the compound serves the same second messenger function in carbachol and glucose stimulated insulin release. Receptor agonist-induced DAG is generated in the plasma membrane which could also occur after the transfer of newly synthesized PA to the membrane. Indeed, phosphatidate phosphohydrolase has been sug- gested to be a plasma membrane-associated enzyme in islets (40). Finally, glucose appears to activate protein kinase $C$ with a similar time course to DAG generation, as judged from protein phosphorylation patterns in intact islets (15). The converging evidence as well as the time course of changes in total DAG mass support the contention that DAG acts as a second messenger in both fuel- and receptor-mediated insulin secretion.

\section{Acknowledgments}

We are very grateful to D. Nappey and C. Bartley for their excellent technical assistance. We thank Dr. Robert Farese for his advice and helpful discussions. The secretarial help of J. Corderoy-Mange and C.-L. Moriaud is also gratefully acknowledged.

This work was supported by the Swiss National Science Foundation (grants 3.214-0.85, 3840-0.83, and 3.246-0.82).

\section{References}

1. Nishizuka, Y. 1984. The role of protein kinase $C$ in cell surface signal transduction and tumour promotion. Nature (Lond.). 308:693698.

2. Bell, R. M. 1986. Protein kinase C activation by diacylglycerol second messengers. Cell. 45:631-632.

3. Berridge, M. J., and R. F. Irvine. 1984. Inositol trisphosphate, a novel second messenger in cellular signal transduction. Nature (Lond.) 312:315-321.

4. Berne, C. 1975 . The metabolism of lipids in mouse pancreatic islets. The biosynthesis of triacylglycerols and phospholipids. Biochem. J. 152:667-673.

5. Dunlop, M. E., and R. G. Larkins. 1985. Pancreatic islets synthesize phospholipids de novo from glucose via acyl-dihydroxyacetone phosphate. Biochem. Biophys. Res. Commun. 132:467-473.

6. Wollheim, C. B., and G. W. G. Sharp. 1981. Regulation of insulin release by calcium. Physiol. Rev. 61:914-973.

7. Wollheim, C. B., and T. J. Biden. 1986. Signal transduction in insulin secretion: comparison between fuel stimuli and receptor agonists. Ann. N.Y. Acad. Sci. 488:317-333.

8. Zawalich, W., C. Brown, and H. Rasmussen. 1983. Insulin secretion: combined effects of phorbol ester and A23187. Biochem. Biophys. Res. Commun. 117:448-455.

9. Streb, H., R. F. Irvine, M. J. Berridge, and I. Schulz. 1983. Release of $\mathrm{Ca}^{2+}$ from a nonmitochondrial intracellular store in pancreatic acinar cells by inositol-1,4,5-trisphosphate. Nature (Lond.) 306:67-69.

10. Prentki, M., T. J. Biden, D. Janjic, R. F. Irvine, M. J. Berridge, and C. B. Wollheim. 1984. Rapid mobilization of $\mathrm{Ca}^{2+}$ from rat insulinoma microsomes by inositol-1,4,5-trisphosphate. Nature (Lond.) 309:562-564.

11. Wollheim, C. B., and T. J. Biden. 1986. Second messenger function of inositol 1,4,5-trisphosphate. Early changes in inositol phosphates, cytosolic $\mathrm{Ca}^{2+}$, and insulin release in carbamylcholinestimulated RINm5F cells. J. Biol. Chem. 261:8314-8319.

12. Henquin, J. C., and H. P. Meissner. 1984. Significance of ionic fluxes and changes in membrane potential for stimulus-secretion coupling in pancreatic B-cells. Experientia (Basel). 40:1043-1052.

13. Malaisse, W. J., M. E. Dunlop, P. C. F. Mathias, F. MalaisseLagae, and A. Sener. 1985. Stimulation of protein kinase $C$ and insulin release by 1-oleoyl-2-acetyl-glycerol. Eur. J. Biochem. 149:23-27.

14. Hutton, J. C., M. Peshavaria, and K. W. Brockelhurst. 1984. Phorbol ester stimulation of insulin release and secretory-granule protein phosphorylation in a transplantable rat insulinoma. Biochem. $J$. 224:483-490.

15. Dunlop, M. E., and R. G. Larkins. 1986. Glucose-induced phospholipid-dependent protein phosphorylation in neonatal rat islets. Arch. Biochem. Biophys. 248:562-569. 
16. Bligh, E. G., and W. J. Dyer. 1959. A rapid method of total lipid extraction and purification. Can. J. Biochem. Physiol. 37:911-917.

17. Banschbach, M. W., R. L. Geison, and J. F. O'Brien. 1974. Use of $\left[1-{ }^{14} \mathrm{C}\right]$ acetic anhydride to quantitate diglycerides: a new analytical procedure. Anal. Biochem. 59:617-627.

18. Banschbach, M. W., R. L. Geison, and M. Hokin-Neaverson. 1981. Effects of cholinergic stimulation on levels and fatty acid composition of diacylglycerols in mouse pancreas. Biochim. Biophys. Acta. 663:34-45.

19. Jolles, J., H. Zwiers, A. Dekker, K. W. A. Wirtz, and W. H. Gispen. 1981. Corticotropin-(1-24)-tetracosapeptide affects protein phosphorylation and polyphosphoinositide metabolism in rat brain. Biochem. J. 194:283-291.

20. Kuksis, A. 1975. In Analysis of Lipids and Lipoproteins. E. G. Perkins, editor. American Oil Chemical Society. 23-26.

21. Hughes, B. P., K.-A. Rye, L. B. Pickford, G. J. Barritt, and A. H. Chalmers. 1984. A transient increase in diacylglycerols is associated with the action of vasopressin on hepatocytes. Biochem. J. 222:535-540.

22. Bocckino, S. B., P. F. Blackmore, and J. H. Exton. 1985. Stimulation of 1,2-diacylglycerol accumulation in hepatocytes by vasopressin, epinephrine, and angiotensin II. J. Biol. Chem. 260:14201-14207.

23. Cockcroft, S., and D. Allan. 1984. The fatty acid composition of phosphatidylinositol, phosphatidate and 1,2-diacylglycerol in stimulated human neutrophils. Biochem. J. 222:557-559.

24. Janjic, D., and C. B. Wollheim. 1983. Interaction of $\mathrm{Ca}^{2+}, \mathrm{Mg}^{2+}$ and $\mathrm{Na}^{+}$in regulation of insulin release from rat islets. Am. J. Physiol. 244:E222-E229.

25. Ashcroft, S. J., C. J. Hedeskov, and P. J. Randle. 1970. Glucose metabolism in mouse pancreatic islets. Biochem. J. 118:143-154.

26. Farese, R. V., P. E. DiMarco, D. E. Barnes, M. A. Sabir, R. E. Larson, J. S. Davis, and A. D. Morrison. 1986. Rapid glucose-dependent increases in phosphatidic acid and phosphoinositides in rat pancreatic islets. Endocrinology. 118:1498-1503.

27. Biden, T. V., B. Peter-Riesch, W. Schlegel, and C. B. Wollheim. 1987. $\mathrm{Ca}^{2+}$-mediated generation of inositol 1,4,5-trisphosphate and inositol 1,3,4,5-tetrakisphosphate in pancreatic islets. Studies with $\mathrm{K}^{+}$, glucose, and carbamylcholine. J. Biol. Chem. 262:3567-3571.

28. Turk, J., B. A. Wolf, J. B. Lefkowith, W. T. Stump, and M. L. McDaniel. 1986. Biochim. Biophys. Acta. 879:399-409.

29. Morgan, N. G., G. M. Rumford, and W. Montague. 1985. Studies on the role of inositol trisphosphate in the regulation of insulin secretion from isolated rat islets of Langerhans. Biochem. J. 228:713718.

30. Dunlop, M. E., and R. G. Larkins. 1986. Muscarinic-agonist and guanine nucleotide activation of polyphosphoinositide phosphodiesterase in isolated islet-cell membranes. Biochem. J. 240:731-737.

31. Holub, B. J., and A. Kuksis. 1978. Metabolism of molecular species of diacylglycerolphospholipids. Adv. Lipid Res. 16:1-125.

32. Dunlop, M. E., and R. G. Larkins. 1984. Activity of endogenous phospholipase $C$ and phospholipase $A_{2}$ in glucose stimulated pancreatic islets. Biochem. Biophys. Res. Commun. 120:820-827.

33. Dunlop, M. E., and W. J. Malaisse. 1986. Phosphoinositide phosphorylation and hydrolysis in pancreatic islet cell membrane. Arch. Biochem. Biophys. 244:421-429.

34. Tanigawa, K., H. Kuzuya, H. Imura, H. Taniguchi, S. Baba, Y. Takai, and Y. Nishizuka. 1982. Calcium-activated, phospholipid-dependent protein kinase in rat pancreas islets of Langerhans. Its possible role in glucose-induced insulin release. FEBS (Fed. Eur. Biochem. Soc.) Lett. 138:183-186.

35. Yamamoto, S., T. Nakaki, T. Nakadate, and R. Kato. 1982. Insulinotropic effects of exogenous phospholipase $A_{2}$ and $C$ in isolated pancreatic islets. Eur. J. Pharmacol. 86:121-124.

36. Trus, M. D., C. S. Hintz, J. B. Weinstein, A. D. Williams, A. S. Pagliara, and F. M. Matschinsky. 1979. A comparison of the effects of glucose and acetylcholine on insulin release and intermediary metabolism in rat pancreatic islets. J. Biol. Chem. 254:3921-3929.

37. Best, L., and W. J. Malaisse. 1984. Nutrient and hormone-neurotransmitter stimuli induce hydrolysis of polyphosphoinositides in rat pancreatic islets. Endocrinology. 115:1814-1820.

38. Best, L., and W. J. Malaisse. 1984. Enhanced de novo synthesis of phosphatidic acid and phosphatidylinositol in rat pancreatic islets exposed to nutrient or neurotransmitted stimuli. Arch. Biochem. Biophys. 234:253-257.

39. Asplund, K., and C. Hellerström. 1972. Glucose metabolism of pancreatic islets isolated from neonatal rats. Horm. Metab. Res. 4:159-163.

40. Dunlop, M., and R. G. Larkins. 1985. Presence of membraneassociated phosphatidate phosphohydrolase activity in cultured islets and its stimulation by glucose. FEBS (Fed. Eur. Biochem. Soc.) Lett. 193:231-235.

41. Malaisse, W. J., A. R. Carpinelli, and A. Sener. 1981. Stimulus-secretion coupling of glucose-induced insulin release. Timing of early metabolic, ionic, and secretory events. Metab. Clin. Exp. 30:527-532.

42. Matschinsky, F. M., A. K. Ghosh, M. D. Meglasson, M. Prentki, V. June, and D. von Allman. 1986. Metabolic concomitants in pure, pancreatic beta cells during glucose-stimulated insulin secretion. J. Biol. Chem. 261:14057-14061.

43. Vara, E., and J. Tamarit-Rodriguez. 1986. Glucose stimulation of insulin secretion in islets of fed and starved rats and its dependence on lipid metabolism. Metab. Clin. Exp. 35:266-271.

44. Thomas, A. P., J. S. Marks, K. E. Coll, and J. R. Williamson. 1983. Quantitation and early kinetics of inositol lipid changes induced by vasopressin in isolated and cultured hepatocytes. J. Biol. Chem. 258:5716-5725.

45. Griendling, K. K., S. E. Rittenhouse, T. A. Brock, L. S. Ekstein, M. A. Gimbrone, Jr., and R. W. Alexander. 1986. Sustained diacylglycerol formation from inositol phospholipids in angiotensin II-stimulated vascular smooth muscle cells. J. Biol. Chem. 261:5901-5906.

46. Trimble, E. R., R. Bruzzone, T. J. Biden, and R. V. Farese. 1986. Secretin induces rapid increases in inositol trisphosphate, cytosolic $\mathrm{Ca}^{2+}$ and diacylglycerol as well as cyclic AMP in rat pancreatic acini. Biochem. J. 239:257-261.

47. Best, L., S. Tomlinson, P. T. Hawkins, and C. P. Downes. 1987. Production of inositol tetrakisphosphate in stimulated pancreatic islets. Biochim. Biophys. Acta. 927:112-116.

48. Laychock, S. G. 1983. Identification and metabolism of polyphosphoinositides in isolated islets of Langerhans. Biochem. $J$. 216:101-106.

49. Dunlop, M. E., and R. G. Larkins. 1984. The role of calcium in phospholipid turnover following glucose stimulation in neonatal rat cultured islets. J. Biol. Chem. 259:8407-8411.

50. Vallar, L., T. J. Biden, and C. B. Wollheim. 1987. Guanine nucleotides induce $\mathrm{Ca}^{2+}$-independent insulin secretion from permeabilized RINm5F cells. J. Biol. Chem. 262:5049-5056. 